\title{
B-Type Natriuretic Peptide as Prognostic Marker in Newly Diagnosed Acute Coronary Syndrome Patients
}

\author{
Jakia Sultana Shila ${ }^{1 *}$ \\ Shirin Akter Begum² \\ Md Aminul Haque Khan \\ Noortaj Begum' \\ Md Matiur Rahman ${ }^{3}$ \\ Dilshad Parvin ${ }^{4}$
}

${ }^{1}$ Department of Biochemistry

Enam Medical College, Savar, Dhaka, Bangladesh.

${ }^{2}$ Department of Obstetrics \& Gynecology

Bangabandhu Sheikh Mujib Medical University

Dhaka, Bangladesh.

${ }^{3}$ Department of Biochemistry

Bangabandhu Sheikh Mujib Medical University

Dhaka, Bangladesh.

${ }^{4}$ National Institute of Cardiovascular Diseases Dhaka, Bangladesh.

\section{*Correspondence to:}

\section{Dr. Jakia Sultan Shila}

Assistant Professor

Department of Biochemistry

Enam Medical College, Dhaka, Bangladesh.

Mobile: +88 01727-222372

E-mail: jakiasshila@hotmail.com

\begin{abstract}
Background: B-type Natriuretic Peptide (BNP) a neurohormone synthesized in ventricular myocardium and released into the circulation in response to ventricular dilatation and pressure overload, is a current biomarker used for identifying patients at high risk of Acute Coronary Syndrome (ACS). High level of BNP is associated with an increased risk of Major Adverse Cardiac Events (MACE) including new or progressive heart failure and myocardial infarction. The objective of this study was to assess the prognosis of newly diagnosed ACS patients by using plasma BNP level. Methods: This study was conducted in the department of Biochemistry, Bangabandhu Sheikh Mujib Medical University (BSMMU) in collaboration with National Institute of Cardiovascular Disease (NICVD) from January 2013 to December 2013. Total 100 newly diagnosed ACS patients, aged 30 to 70 years, irrespective of sex who reported within 24 hours of onset of symptoms were enrolled in this study by purposive and convenient sampling. Plasma BNP level of selected study subjects was measured within 24 hours of onset of symptoms. Then subjects were grouped on the basis of their empirical cut-off value of plasma BNP concentration Group I having plasma BNP level $<135 \mathrm{pg} / \mathrm{mL}$ and Group II having plasma BNP level $135 \mathrm{pg} / \mathrm{mL}$. Results: Of 100 ACS patients, 86 were male and 14 were female with the mean age $49.61 \pm 10.28$ years and the age range of 30 to 70 years. Among 26 patients in Group I, good recovery, morbidity and mortality were $22(84.6 \%), 4(15.4 \%)$ and zero and among 74 patients in Group II good recovery, morbidity and mortality were $18(24.3 \%), 53(71.6 \%)$ and $3(3.0 \%)$ respectively. Differences in outcome between groups were statistically significant $(\mathrm{P}=0.001)$. Above the empirical cut-off value of BNP $(135 \mathrm{pg} / \mathrm{mL})$ good prognosis was for 18 $(24.3 \%)$ and bad prognosis was for $56(75.7 \%)$ patients and relative risk 3.48 in 95\% CI (2.25-5.36). Conclusion: It can be concluded from this study that higher baseline plasma BNP concentration is associated with more adverse clinical outcomes in ACS patients. Since the baseline plasma BNP concentrations at the onset of event shows incremental prognostic value, so plasma BNP can be used clinically as a biomarker of prognosis in ACS patients.
\end{abstract}

Key words: B-type Natriuretic Peptide (BNP); Acute Coronary Syndrome (ACS); Major Adverse Cardiac Events (MACE).

\section{INTRODUCTION}

Acute Coronary Syndrome (ACS) refers to a group of cardiac disorders including Unstable Angina (UA), ST-elevation Myocardial Infarction (STEMI) and Non STElevation Myocardial Infarction (NSTEMI) attributed to the various degree of ischemia ${ }^{1}$. 
Ischemic Heart disease (IHD) is the leading cause of disability and death in most countries of the world ${ }^{1}$. It will be the largest cause of death and disability in the world by $2020^{2}$. Approximately 450,000 people in the United States die from coronary artery disease per year. Recent studies have shown that around 840,000 patients diagnosed with ACS are admitted to hospitals in America ${ }^{3}$. The prevalence of coronary heart disease in Bangladesh was found to be 33 per 10000 in 1976, which has increased more than five-fold to be 172 per 10000 in $1998^{4}$. In the inter-heart study, Bangladesh has the highest prevalence of most risk factors compared to people in other South Asian countries ${ }^{5}$.

The pathogenesis of ACS involves an intricate interplay among the endothelium, the inflammatory cells and the thrombogenecity of blood ${ }^{6}$. Coronary atherosclerosis complicated by plaque rupture (fissure) and subsequent thrombosis is the main cause of acute ischemic syndromes ${ }^{7}$. Approximately $75 \%$ of all coronary thrombi responsible for ACS are precipitated by plaque rupture ${ }^{8}$. After either plaque rupture or endothelial erosion, the subendothelial matrix (which is rich in tissue factor, a potent procoagulant) is exposed to the circulating blood; this exposure leads to platelet adhesion followed by platelet activation and aggregation and the subsequent formation of a thrombus ${ }^{9}$.

Current biomarkers used for identifying patients at high risk of ACS primarily include biomarkers of myocardial necrosis (troponin, CK-MB, myoglobin), or ischemia and myocardial stretch $(\mathrm{BNP})^{10}$. Brain natriuretic peptide (BNP) is a 32 -aminoacid neurohormone synthesized in ventricular myocardium and released into the circulation in response to ventricular dilatation and pressure overload, first identified in extracts of porcine brain $^{11}$. BNP belongs to the natriuretic peptide family. It comprises structurally similar peptides atrial natriuretic peptide (ANP), BNP, C-type natriuretic peptide (CNP) and Dtype natriuretic peptide. BNP expression and release from cardiomyocites can also be stimulated by a variety of endocrine, paracrine and autocrine factors ${ }^{12}$. The plasma level of BNP is elevated in patients with congestive heart failure and increases in proportion to the degree of left ventricular dysfunction and the severity of symptoms of heart failure ${ }^{13}$. After acute myocardial infarction, levels of BNP rise rapidly during the first 24 hours and then tend to stabilize. Measurement of the level of BNP between one and four days after a transmural infarction provides prognostic information that is independent of the left ventricular ejection fraction and other important base-line variables ${ }^{12}$.

In one study high level of BNP was found associated with an increased risk of major adverse cardiac events (MACE) including new or progressive heart failure and myocardial infarction ${ }^{14}$. The mortality and morbidity in ACS is high due to lack of reliable and accurate scale of risk stratification following the onset of events. Therefore we designed this study to assess the prognosis of newly diagnosed ACS patients by using BNP, and thereby take appropriate therapeutic regimen to prevent further complications.

\section{MATERIALS AND METHODS}

This prognostic cohort study was carried out in the department of Biochemistry, Bangabandhu Sheikh Mujib Medical University (BSMMU), in collaboration with National Institute of Cardiovascular Disease (NICVD) from January 2013 to December 2013. Total 100 newly diagnosed ACS patients, aged 30 to 70 years, irrespective of sex who reported within 24 hours of symptom onset were enrolled in the study by purposive and convenient sampling. The purpose and procedure of the study were discussed with the subjects who fulfilled the enrollment criteria. Patients who had history of previous ischemic heart disease, heart failure, severe renal failure, severe liver disease and thyroid disorder were excluded from the study. Written informed consent was taken from those who agreed to participate in the study. Plasma BNP level was measured within 24 hours of symptom onset of selected study subjects. Data were collected from the selected subjects on variables of interest using a data collection sheet by interview, observation, clinical examination, serological investigations and from the history sheet of the patients. After measurement of plasma BNP concentration subjects were grouped on the basis of their empirical cut-off value of plasma BNP concentration. Group I included subjects having plasma BNP level $<135 \mathrm{pg} / \mathrm{mL}$ and Group II having plasma BNP level $135 \mathrm{pg} / \mathrm{mL}$. Then all patients were treated and managed by conventional standard management protocol during their hospital stay and up to 3 months. Prognosis was assessed by a review of medical records, and follow-up telephone interview.

Follow-up time was defined as the time from admission to the first cardiac event or, for patient without an event, from admission up to 3 months. During hospital stay and during their follow-up period, patients were assessed clinically for any kind of clinical outcomes like good recovery, morbidity (like recurrent MI, heart failure, arrhythmia, cardiogenic shock, coronary stenosis where revascularization was needed) and mortality. Patients were also evaluated on the basis of ECG, Echocardiogram, Coronary Angiogram (CAG), cardiac markers according to the merit of individual case. At the end of follow-up, patients' clinical outcomes were analyzed on the basis of their baseline plasma BNP concentrations. Data were analyzed using SPSS version 16.0 and presented by tables, graphs, and charts as needed. Result was expressed as mean $\pm \mathrm{SD}$, median, in numbers and percentages. Comparisons were done by t-test, Chi-square test, Spearman rank correlation test, Kruskal-Walli's H test.

\section{RESULTS}

Among the $100 \mathrm{ACS}$ patients 86 were male and 14 were female with the mean age $49.61 \pm 10.28$ years and the age range of 30 to 70 years. Table 1 shows the distribution of study subjects by age and sex. Among the males, 31 (36.0\%) patients belonged to the age group 5059 years followed by $21(24.4 \%)$ patients in age group 4049 years. There were 18 (20.9\%) patients in age group 60 years and $16(18.6 \%)$ patients were in age group 30 39 years. Among the females, $5(35.7 \%)$ patients belonged to the age group 4049 years followed by $4(28.6 \%)$ patients in age group 5059 years, $3(21.4 \%)$ patients in age group 60 years and $2(14.3 \%)$ patients were in age group 3039 years. Mean age in male was $49.31 \pm 10.12$ years and in female $49.50 \pm 10.27$ years with no significant difference between male and female. 
Table 1 : Distribution of study subjects by age and sex $(n=100)$

\begin{tabular}{lrrr} 
Age (years) & \multicolumn{2}{c}{ Sex } & p value \\
& \multicolumn{1}{c}{ Male } & Female & \\
3039 & $16(18.6)$ & $2(14.3)$ & \\
4049 & $21(24.4)$ & $5(35.7)$ & \\
5059 & $31(36.1)$ & $4(28.6)$ & \\
$>60$ & $18(20.9)$ & $3(21.4)$ & \\
Total & $86(100.0)$ & $14(100.0)$ & \\
Mean \pm SD & $49.31 \pm 10.12$ & $49.50 \pm 10.27$ & 0.966 \\
\hline
\end{tabular}

$\mathrm{t}$-test was done to measure the level of significance

Parentheses in the table indicate percentage.

Among the study subjects 26 were in Group I (plasma BNP value $<135.0 \mathrm{pg} / \mathrm{mL}$ ) and 74 in Group II (plasma BNP value $>135.0 \mathrm{pg} / \mathrm{mL}$ ). Out of total ACS patients, 65 had ST-elevation myocardial infarction (STEMI), 30 had non ST-elevation myocardial infarction (NSTEMI) and rest 5 had unstable angina (UA) (Fig 1).

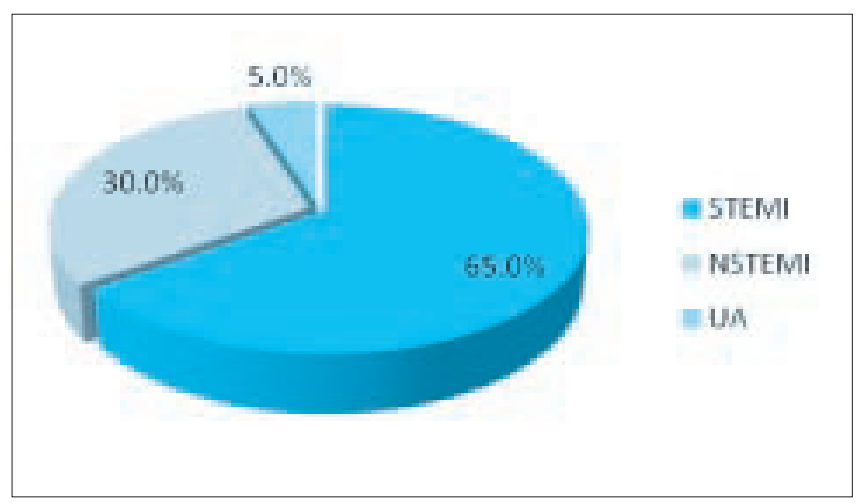

Figure 1: Clinical types of the ACS patients

Table 2 shows comparison of baseline parameters between the groups of study subjects according to plasma BNP values. In Group I and Group II mean age was 46.00土9.85 and $50.88 \pm 10.19$ years respectively. There was statistically significant difference in age between two groups $(\mathrm{p}=0.037)$. In Group I males were $20(76.9 \%)$ and females $6(23.1 \%)$ and in Group II males were $66(89.2 \%)$ and females $8(10.8 \%)$ respectively. There was no statistical significant difference in sex between two groups $(\mathrm{p}=0.121)$. Regarding smoking, hypertension and diabetes Group I contained 16 (61.5\%), 14 $(53.8 \%)$ and $7(26.9 \%)$ patients respectively and Group II contained $45(60.8 \%), 39(52.7 \%)$ and 19 (25.7\%) patients respectively. No significant difference was found between two groups.
Table 2: Comparison of baseline characteristics of study subjects according to plasma BNP levels

\begin{tabular}{|c|c|c|c|}
\hline $\begin{array}{l}\text { Baseline } \\
\text { characteristics }\end{array}$ & $\begin{array}{r}\text { Plasma B } \\
\text { Group I }(n=26) \\
(<135 \mathrm{pg} / \mathrm{mL})\end{array}$ & $\begin{array}{l}\text { VP } \\
\text { Group II }(\mathrm{n}=74) \\
(>135 \mathrm{pg} / \mathrm{mL})\end{array}$ & p values \\
\hline Age (years) & $46.00 \pm 9.85$ & $50.88 \pm 10.19$ & $0.037 \#$ \\
\hline \multicolumn{4}{|l|}{ Sex } \\
\hline Male & $20(76.9)$ & $66(89.2)$ & $0.121 *$ \\
\hline Female & $6(23.1)$ & $8(10.8)$ & \\
\hline Smoking habit & $16(61.5)$ & $45(60.8)$ & $0.948^{*}$ \\
\hline Hypertension & $14(53.8)$ & $39(52.7)$ & $0.920 *$ \\
\hline Diabetes & $7(26.9)$ & $19(25.7)$ & $0.901 *$ \\
\hline
\end{tabular}

*Chi-square test was done to measure the level of significance. \#t-test was done to measure the level of significance.

Parentheses in the table indicate percentage.

The prognostic outcome of ACS patient in relation to plasma BNP level is described in Table 3. In Group I among 26 patients good recovery, morbidity and mortality were found 22 $(84.6 \%), 4(15.4 \%)$ and $0(0.0 \%)$ and in Group II among 74 patients good recovery, morbidity and mortality were found 18 $(24.3 \%), 53(71.6 \%)$ and $3(3.0 \%)$ respectively. In Group II we found significantly low good recovery but high morbidity and mortality compared with Group I ( $\mathrm{p}=0.001)$.

Table 3: Prognostic outcome of ACS patients on the basis of BNP

\begin{tabular}{lrrr} 
Prognosis & $\begin{array}{c}\text { Group I } \\
(<135 \mathrm{pg} / \mathrm{mL}) \\
\text { Number }(\%)\end{array}$ & $\begin{array}{c}\text { Group II } \\
(>135 \mathrm{pg} / \mathrm{mL})\end{array}$ & p value \\
Number $(\%)$ & \\
Good prognosis & $22(84.6)$ & $18(24.3)$ & 0.001 \\
Morbidity & $4(15.4)$ & $53(71.6)$ & \\
Mortality (death) & $0(0.0)$ & $3(4.1)$ & \\
Total & $26(100.0)$ & $74(100.0)$ & \\
\hline
\end{tabular}

Chi-square test was done to measure the level of significance Parentheses in the table indicate percentage.

The importance of cardiac marker concentration (BNP) in relation to prognosis of ACS patients is described in Table 4. Median value of good recovery, morbidity and mortality were 132.84, 350.72, $820.90 \mathrm{pg} / \mathrm{mL}$ respectively. The table also shows that BNP values were increasing with the severity of bad prognosis and that was statistically significant by KruskalWallis $H$ test $(\mathrm{p}=0.001)$. 
Table 4: Importance of BNP concentration with prognosis outcome $(\mathrm{n}=100)$

\begin{tabular}{ccccc} 
Cardiac & Prognosis & p value \\
marker & $\begin{array}{c}\text { Good recovery } \\
\text { Median } \\
\text { (range) }\end{array}$ & $\begin{array}{c}\text { Morbidity } \\
\text { Median } \\
\text { (range) }\end{array}$ & $\begin{array}{c}\text { Mortality } \\
\text { Median } \\
\text { (range) }\end{array}$ & \\
\hline BNP (pg/mL) & 132.84 & 350.72 & 820.90 & 0.001 \\
& $(67-1175)$ & $(103.45-2685.83)$ & $(267-1947.35)$ & \\
\hline
\end{tabular}

Kruskal-Wallis H test was done to measure the level of significance.

Above the empirical cut-off value of BNP (135 pg/mL) good prognosis was for $18(24.3 \%)$ and bad prognosis was for 56 (75.7\%) patients and RR 3.48 in 95\% CI (2.25?5.36). It indicates 3.48 times more chance of having bad prognosis in Group II patients in 95\% CI. (Table 5).

Table 5: Risk of morbidity and mortality in patients with high BNP level $(n=100)$

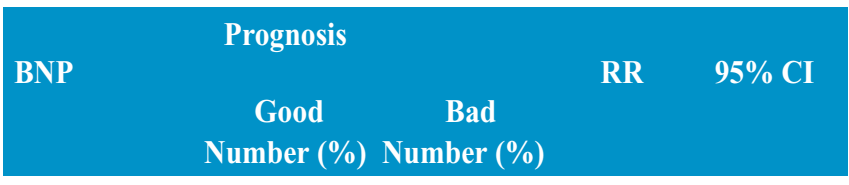

Group I

$(<135 \mathrm{pg} / \mathrm{mL}) \quad 22(84.6) \quad 4(15.4)$

$3.479 \quad 2.254-5.369$

Group II

$(>135 \mathrm{pg} / \mathrm{mL}) \quad 18(24.3) \quad 56(75.7)$

Parentheses in the table indicate percentage.

Spearman rank correlation test of serum BNP with prognosis showed $r$ value $=0.488$ and $p$ value $=0.001$. Prognosis is significantly correlated with concentration of biomarker (Fig 2).

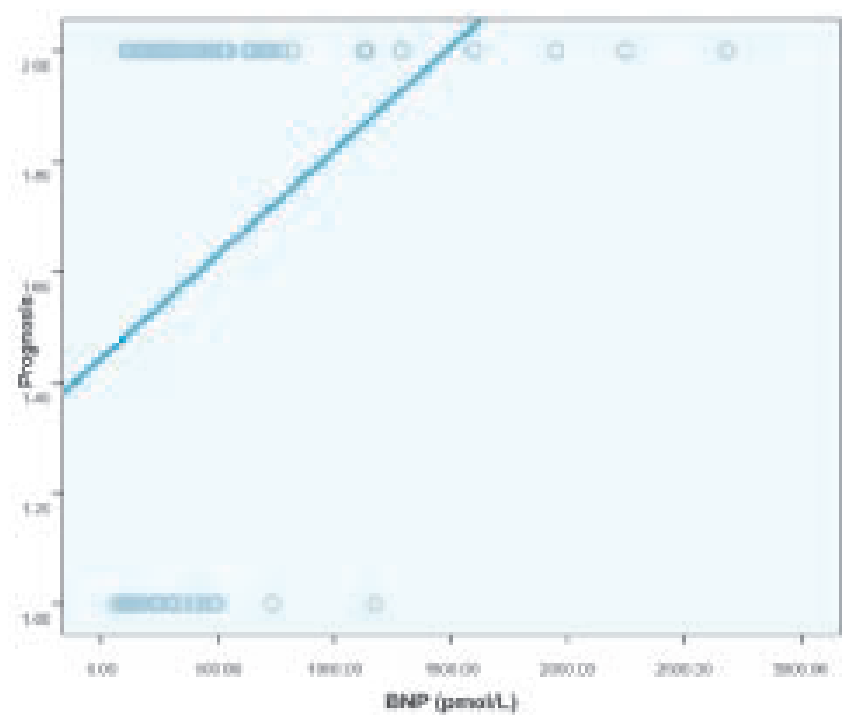

Figure 2: Correlation of BNP with prognosis. Spearman rank correlation $r$ is 0.488 and $p$ value is 0.001 . Prognosis: 1 represents good and 2 represents bad.

\section{DISCUSSION}

Coronary Heart Disease (CHD) is the leading cause of mortality and morbidity affecting millions of peoples in both developed and developing countries. Clinical criteria, electrocardiographic criteria and conventional laboratory tests do not adequately predict the risk of cardiovascular events in patients presenting with ACS. Plasma BNP concentration of all study subjects were measured at enrollment and then divided into two groups on the basis of empirical cut-off value (Group I having plasma BNP level $<135 \mathrm{pg} / \mathrm{mL}$ and Group II having plasma BNP level $135 \mathrm{pg} / \mathrm{mL}$ ). The study subjects of two groups were identical irrespective of sex, history of smoking, hypertension and diabetes but age was significantly higher in Group II ( $p=0.037)$. Similar findings were observed by them ${ }^{15}$. In multiple linear regression analysis they showed that $\mathrm{N}-$ terminal pro-BNP (NT pro-BNP) concentration was mainly associated with age. They also found increased BNP level in female. But in this study we did not find any relationship with the sex. Our finding is consistent with them where they also did not find any significant difference in BNP levels between male and female ${ }^{16}$.

We have found the significant bad outcomes in subjects having increased BNP levels $(p=0.001)$. In our study correlation of prognosis like good and bad outcomes with BNP was statistically significant (Table 5). The relative risk of subjects having higher BNP level was found 3.48 at $95 \% \mathrm{CI}$ (2.25-5.36).

Higher bad clinical outcomes in Group II compared with Group I indicate that the increasing baseline plasma BNP concentration is associated with worsening clinical outcomes. This result is consistent with them ${ }^{16}$. In their multivariate analysis, they showed that BNP was the independent predictive value for 7 days' categorical outcome in patients admitted with chest pain (Logistic regression $p=0.001$, $R$ square $=0.741$ ). Our findings are also consistent with findings of them ${ }^{11}$. They demonstrated that a single measurement of plasma BNP levels provides powerful information for use in risk stratification across the entire spectrum of ACS. They found that increasing quartiles of plasma NT pro-BNP was associated with a greater risk of death or cardiovascular events, with annual event rate $2.6 \%$ in the lowest quartile to annual event rate $19.6 \%$ in highest quartile ${ }^{17}$. That means elevated level of plasma NT proBNP in ACS predicts cardiovascular morbidity and mortality independent of other prognostic markers. Another study found that baseline BNP level higher than $80 \mathrm{pg} / \mathrm{mL}$ was associated with 2-fold higher long term risk of death (adjusted hazard ratio [HR], 2.1; 95\% CI). They also observed that high levels of BNP during ACS strongly predict risk for death and incident congestive heart failure (HR 2.5) ${ }^{18}$.

In our study prognostic outcomes of the study subjects were seen according to the concentration of BNP. We found that with increasing concentrations of BNP, morbidity and mortality also increased. Increasing in BNP concentrations with morbidity and mortality was statistically significant $(p=0.001)$. They found this type of findings in their study ${ }^{19}$. They found the proportion of men with NT pro-BNP concentrations between 100 and $399 \mathrm{ng} / \mathrm{L}$ was significantly lower than the proportion with concentrations $<100 \mathrm{ng} / \mathrm{L}$, it was, however, significantly higher in small group with NT pro-BNP $2000 \mathrm{ng} / \mathrm{L}$ ( $\mathrm{p}=0.001$ and $\mathrm{p}=0.026$ by logistic regression, respectively). 
In a study they demonstrated that baseline plasma BNP $>80$ $\mathrm{pg} / \mathrm{mL}$ was associated with a 2-fold higher long term risk of death (adjusted hazard ratio 2.1) ${ }^{18}$. They found that on multivariant analysis, a baseline BNP level of $>80 \mathrm{pg} / \mathrm{mL}$ was still associated with a near 3- fold higher long term risk of CV events (adjusted Relative Risk [RR] 2.63 (95\% CI 1.34 5.19) ${ }^{20}$. The findings of our study suggest that BNP should be measured after an ACS in order to identify patients at high and low risk for adverse outcomes and treatment should be adjusted accordingly.

\section{CONCLUSION}

From this study it can be concluded that higher baseline plasma BNP concentration is associated with more adverse clinical outcomes in ACS patients.
Since the baseline plasma BNP concentrations at the onset of event shows incremental prognostic value, plasma BNP can be used clinically as a biomarker of prognosis in ACS patients.

\section{LIMITATIONS OF THE STUDY}

Our sample size was small and repeated evaluations of BNP levels at subsequent intervals could not be done. Further studies with large sample size and repeated evaluations of BNP are recommended.

\section{DISCLOSURE}

All the authors declared no competing interest.

\section{REFERENCES}

1. Nia HS, Haghdoost AA, Afshar R, Nazari R, Ghana S, Soleimani MA et al. Relationship of some risk factors and symptoms in patients with acute coronary syndrome. Life Science Journal. 2012; 9(4): 695-701.

2. Anwaruddin S, Askari AT, Topol EJ. Redefining risk in acute coronary syndromes using molecular medicine. J Am Coll Cardiol. 2007; 49: 279-289.

3. Rosamond W, Flegal K, Friday G, Furie K, Go A, Haasa N et al. Heart disease and stroke statistics update: a report from the American Heart Association Statistics Committee and Stroke Statistics Subcommittee. Circulation.2007; 6; 115(5): e172.

4. Mohibullah A. Cardiac care service in Bangladesh. Bangladesh Heart Journal. 2009; 24(2): 38-39.

5. Joshi P, Islam S, Pais P, Reddy S, Dorairaj P, Kazmi K et al. Risk factors for early myocardial infarction in South Asians compared with individuals in other countries. J Am Med Assoc. 2007; 297(3): 286-294.

6. Naghavi M, Libby P, Falk E, Casscells SW, Litovsky S, Rumberger J et al. From vulnerable plaque to vulnerable patients: a call for new definitions and risk assessment strategies. Circulation. 2003; 108: 1664-1672.

7. Falk E, Shah PK, Fuster V. Pathogenesis of plaque disruption. In: Fuster V, Ross R, Topol EJ (eds). Atherosclerosis and coronary artery disease (Vol I). Philadelphia-New York: Lippincott-Raven. 1996; 492-510.

8. Falk E, Shah PK, Fuster V. Atherothrombosis and thrombosis-prone plaques. In: Fuster V, Alexander RW, O'Raurke RA (eds). Hurst's the Heart. New York: McGraw-Hill. 2004; 1123-1139.

9. Kumar A, Cannon CP. Acute coronary syndromes: diagnosis and management, Part I. Mayo Clin Proc. 2009; 84(10): 917-938

10. Myeloperoxdase: a novel addition to multimarker testing in acute coronary syndrome. Medco Forum. 2006; 13(32):1-2.

11. De Lemos JA, Morrow DA, Bentley JH, Omland T, Sabatine MS, McCabe et al. The prognostic value of B-type natriuretic peptide in patients with acute coronary syndromes. N Eng J Med. 2001; 345: 1014-1010.

12. Clerico A, Iervasi G, Mariani G. Pathophysiologic relevance of measuring the plasma levels of cardiac natriuretic peptide hormones in humans. Horm Metab Res. 1999; 31(9): 487-498.

13. Yasue H, Yoshimura M, Sumida H. Localization and mechanism of secretion of B-type natriuretic peptide in comparison with those of A-type natriuretic peptide in normal subjects and patients with heart failure. Circulation. 1994; 90: 195-203.

14. Dao Q, Krishnaswamy P, Kazanegra R. Utility of B-type natriuretic peptide in the diagnosis of congestive heart failure in an urgentcare setting. J Am Coll Cardiol. 2001; 37: 379-385.

15. Lorgis L, Zeller M, Dentan G, Sicard P, Buffet P, Huillier L et al. Prognostic value of N-terminal proBrain natriuretic peptide in elderly people with acute myocardial infraction: prospective observational study. BMJ. 2009; 338: 1605.

16. Tabibzadeh A, Hemassi G, Mahboobi H, Yazdani R, Salehi O, Jalalian M. Assessment of correlation between brain natriuretic protein test and early prognosis in acute coronary syndrome. Life Science Journal. 2012; 9(3): 774-780.

17. Bibbins-Domingo K, Gupta R, Beeya NA, Wu AHB, Schiller NB, Whooly NA. N-terminal fragment of the prohormone brain type natriuretic peptide (NT- proBNP) , cardiovascular events and mortality in patients with stable coronary heart disease. J Am Med Assoc. 2007; 297(2): 169-176.

18. Morrow DA, De Lemos JA, Michael AB, Sabatine MS, Sabina AM, Petr J et al. Prognostic value of serial B-type natriuretic peptide testing during follow-up of patients with unstable coronary artery disease. J Am Med Assoc. 2005; 294: 22.

19. Marz W, Tiran B, Seelhorst U, Wellnitz B, Bauersachs J, Bernhard R et al. N-terminal Pro-B-type natriuretic peptide predicts total and cardiovascular mortality in individuals with or without stable coronary artery disease: The Ludwigshafen Risk and Cardiovascular Health Study. Clinical Chemistry. 2007; 53(6): 1075-1083.

20. Ang DSC, Kong CFJ, Kao MPC, Struthers AD. Serial bedside B-type natriuretic peptide strongly predicts prognosis in acute coronary syndrome independent of echocardiographic abnormalities. Am Heart J. 2009; 158(1): 133-140. 